\title{
Elucidating the Mechanism of an RbF Post Deposition Treatment in CIGS Thin Film Solar Cells
}

Tim Kodalle*, Marc D. Heinemann, Dieter Greiner, Hasan A. Yetkin, Michael Klupsch, Chen $\mathrm{Li}^{* *}$, Peter A. van Aken, Iver Lauermann, Rutger Schlatmann,

Christian A. Kaufmann

July 11, 2018

* Corresponding author: tim.kodalle@helmholtz-berlin.de

** Corresponding author regarding STEM: chen.li@fkf.mpg.de

T. Kodalle, Dr. M. D. Heinemann, Dr. D. Greiner, H. A. Yetkin, M. Klupsch, Dr. I. Lauermann, Prof. Dr. R. Schlatmann, Dr. C. A. Kaufmann

PVcomB/Helmholtz-Zentrum Berlin für Materialien und Energie, Schwarzschildstr. 3, 12489

Berlin, Germany

Email: tim.kodalle@helmholtz-berlin.de

H. A. Yetkin

Technical University Berlin, Straße des 17. Juni 135, 10623 Berlin, Germany

Dr. C. Li, Prof. Dr. P. A. van Aken

Max Planck Institute for Solid State Research, Heisenbergstraße 1, 70569 Stuttgart, Germany

Email: chen.li@fkf.mpg.de 
Prof. Dr. R. Schlatmann

Hochschule für Technik und Wirtschaft Berlin, Treskowallee 8, 10318 Berlin, Germany

\begin{abstract}
We investigate the impact of a rubidium fluoride post deposition treatment (RbF-PDT) on the material and device properties of $\mathrm{Cu}(\mathrm{In}, \mathrm{Ga}) \mathrm{Se}_{2}$ (CIGS) thin films and corresponding solar cells. The structure and device properties of CIGS with different PDT duration are compared. With longer PDT duration, which equals a higher amount of RbF deposited on the CIGS absorber layer, we observe a clear trade-off between increasing open-circuit-voltage $\left(V_{\mathrm{OC}}\right)$ and decreasing fill factor $(F F)$. An optimum of the PDT-duration is found increasing the efficiency by about $0.8 \%$ (absolute) compared to the Rb-free reference device. We explore the mechanisms behind the increased $V_{\mathrm{OC}}$ by various characterization methods and identify them as a combination of increased carrier concentration and reduced recombination rates in the device. Possible origins for these mechanisms are discussed. Furthermore numerical simulations are used to analyze the detrimental effect of the PDT on the $F F$. We find that thermally activated alkali migration into the transparent front contact could create acceptor states there, which could explain the observed $F F$-loss.
\end{abstract}

\title{
1 Introduction
}

The effects induced by alkali elements are responsible for the last two periods of significant efficiency increase in $\mathrm{Cu}(\mathrm{In}, \mathrm{Ga}) \mathrm{Se}_{2}$ (CIGS) world record solar cells. While in the years around 1990 it was the incorporation of $\mathrm{Na},{ }^{[1]}$ the use of heavier alkali elements was a major reason for the recent boost of record efficiencies from $20.3 \%$ to $22.9 \%$ in just 6 years. ${ }^{[2,3]}$ Although most of these results were accomplished using a KF-PDT, recent world record publications revealed that cells processed with PDTs using heavier alkali elements, especially Rb, outperform those treated with KF. ${ }^{[4]}$ Although several hypotheses were put forward, little is known about the detailed effects of heavier alkali elements on the material and electrical properties of the CIGS-based devices and many studies still concentrate on $\mathrm{Na}$ and K. Recently there were also studies published investigating the compositional effects of the RbF-PDT on CIGS experimentally, ${ }^{[5-8]}$ and theoretically. ${ }^{[9]}$ 
Furthermore there are also publications investigating the mechanism of the RbF-PDT on an electronic level. ${ }^{[10]}$ However, there are few publications combining all these investigations. ${ }^{[11]}$

Here the impact of an RbF-PDT on the material as well as the device properties of CIGS thin-film solar cells is investigated. Thereby the morphological and compositional changes induced by the RbF-PDT as well as its impact on the device parameters are compared with reference samples free of heavy alkali elements. Furthermore a comprehensive model for the complete effect mechanism induced by the RbF-PDT is proposed. Finally the results are discussed in regard to the literature, in particular KF-PDTs.

\section{Results}

\subsection{Impact of the RbF-PDT on the device properties of CIGS solar cells}

To unveil trends in the effects of the RbF-PDT on the device performance of corresponding CIGS solar cells, the duration of the PDT of otherwise identically processed absorber layers was varied from 0 min up to 20 min at a constant deposition rate. The resulting PV-parameters are represented as boxplots in Figure 1. While there is no correlation visible between the short-circuit current density $\left(j_{\mathrm{SC}}\right)$ and the PDT duration, a clear trade-off between increasing $V_{\text {OC }}$ and decreasing $F F$ is observed as the duration of the RbF-deposition increases. This trade-off leads to an optimum at 10 min with an efficiency enhanced by about $0.8 \%$ (absolute) compared to the Rb-free reference device. The sample that was treated with $\mathrm{RbF}$ for only one minute does not follow this overall trend but shows strongly deteriorated $j_{\mathrm{SC}}, V_{\mathrm{OC}}$ and $F F$. This behavior will be discussed in the following sections.

In Figure 2a the sodium depth profiles of these samples are shown as measured by glow discharge optical emission spectroscopy (GD-OES). These measurements were carried out after the samples were rinsed in $\mathrm{NH}_{3}(\mathrm{aq})$, so that alkali metal ions remaining on the surface were removed. The profiles are corrected for thickness using the onset of the molybdenum signal. The measured profiles reveal that with prolonged rubidium exposure sodium is steadily driven from the absorber layers, leading to an overall lower Na-content within the absorber and especially a flatter Na- 


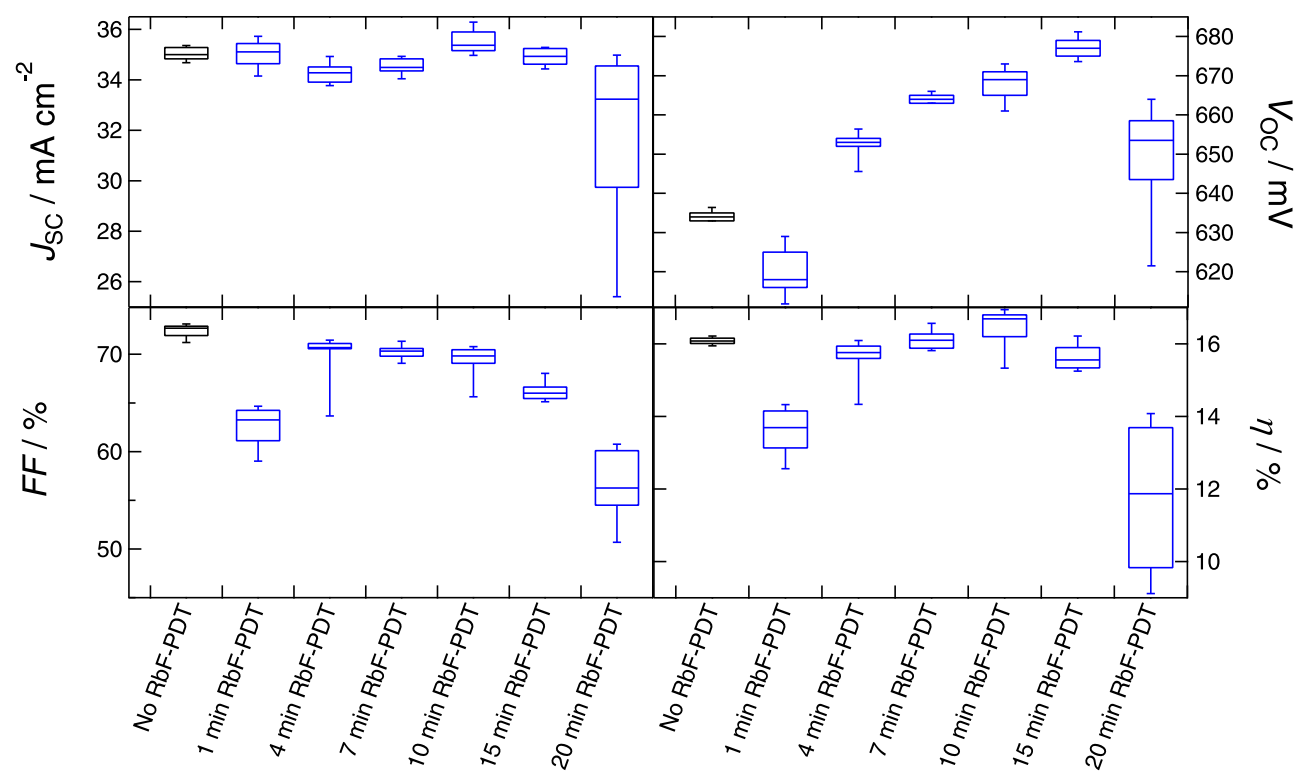

Figure 1: Boxplots of the electrical parameters of CIGS solar cells determined by $j$ - $V$-analysis. Each box represents the values measured on 15 cells of the corresponding substrate.

distribution near the back contact. A very short RbF-PDT leads to a severe reduction of the carrier concentration $n_{\mathrm{CV}}$ (as measured by $C$ - $V$-profiling, Fig. 2b) of almost one order of magnitude, which can explain the drop in $V_{\mathrm{OC}}$ measured for this sample. When deploying longer RbF-PDTs, $n_{\mathrm{CV}}$ is recovered leading to even higher values as measured on the Rb-free reference device at $t_{\mathrm{RbF}-\mathrm{PDT}} \geq 7 \mathrm{~min}$.

In contrast to the beneficial effects of the RbF-PDT on the $V_{\mathrm{OC}}$, a steady decrease in $F F$ is observed even after short PDT-durations (see Fig. 1), which could also previously be observed after KF-PDT on our samples. ${ }^{[12]}$

Furthermore there is a pronounced roll-over effect (reduction of the uprising slope at higher bias voltages) developing in the measured $j$ - $V$-curves after the RbF-PDT. This is exemplary shown with the comparison of the $j$ - $V$-curves of the best reference cell and the best treated cell in Figure 3. 

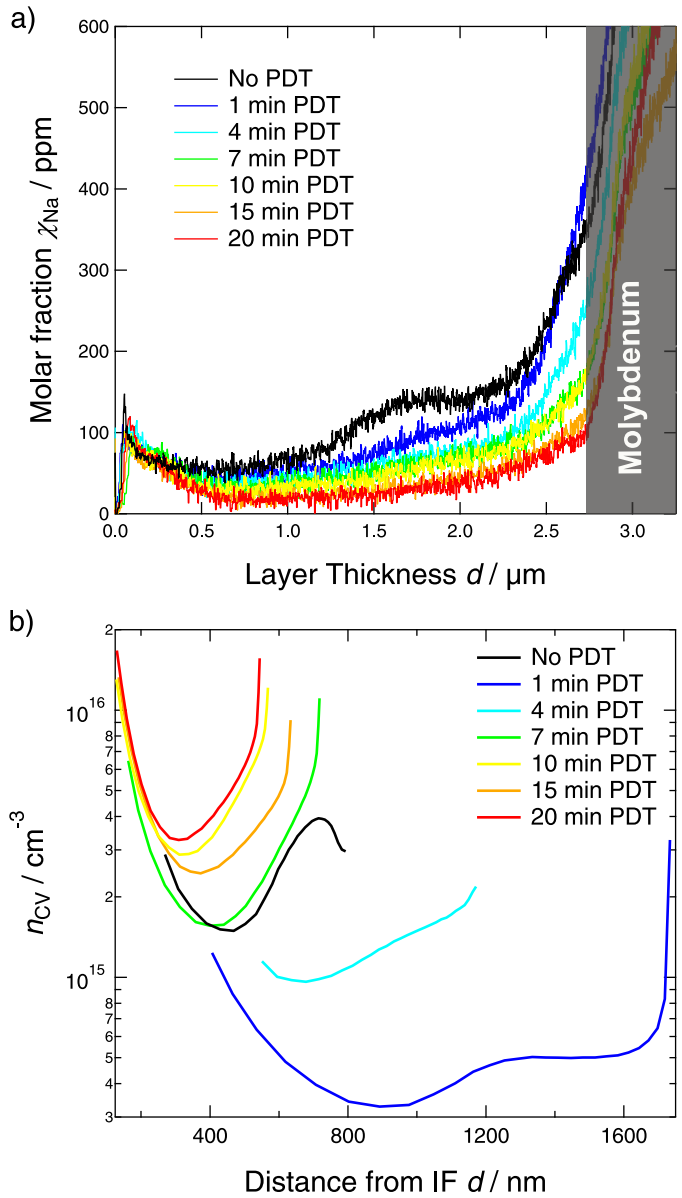

Figure 2: a: GD-OES depth profiles of sodium measured on seven samples with varied RbF-amount deposited. b: $C-V$-profiles of the corresponding solar cells.

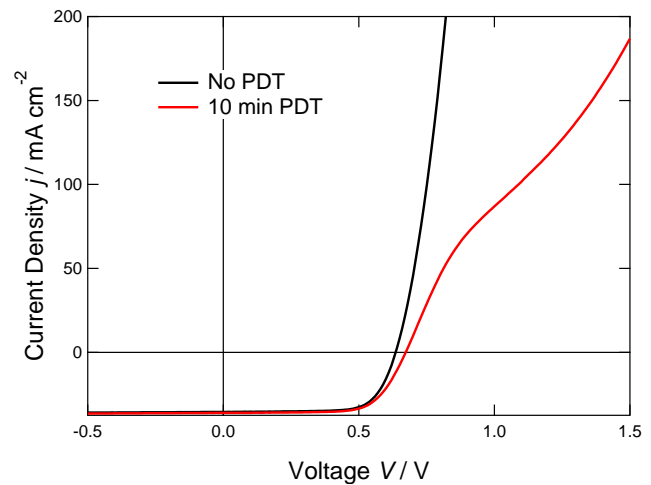

Figure 3: Measured $j$ - $V$-curves of the best reference cell (black, $\eta=16,2 \%$ ) and the best RbFtreated cell (red, $\eta=17,0 \%$ ) of the investigated sample set. 

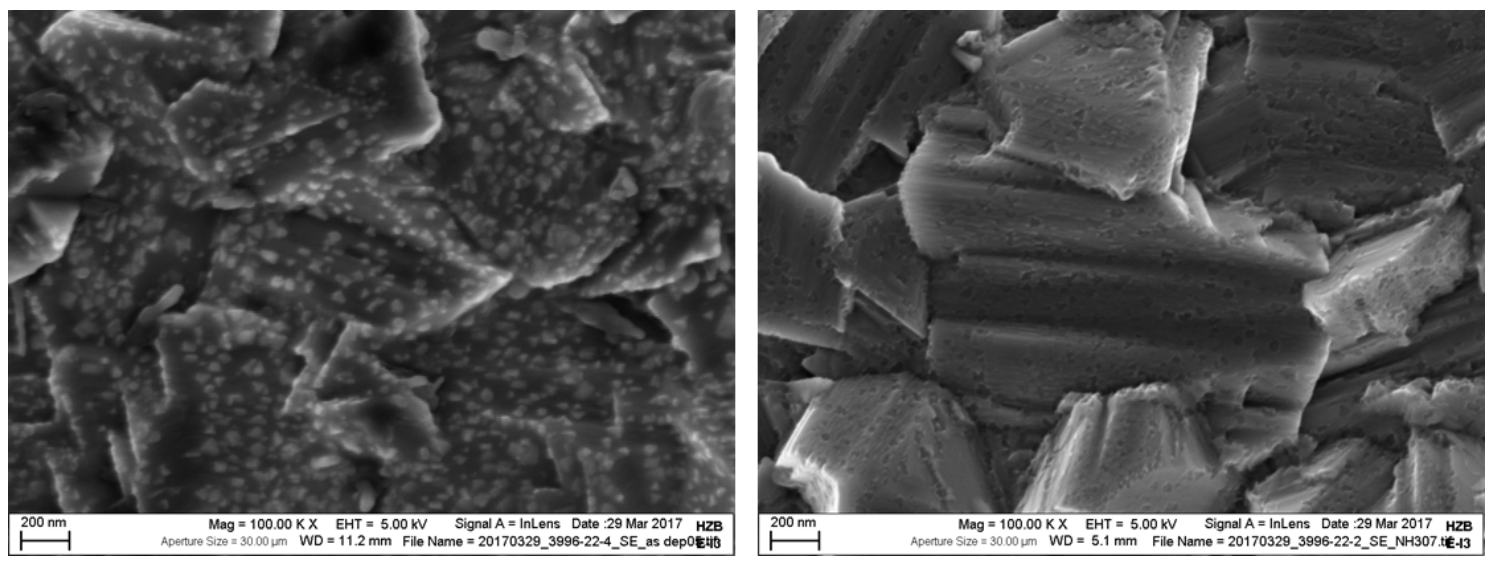

Figure 4: Left: SEM top view image of a CIGS absorber layer's surface directly after the RbF-PDT. Right: SEM top view image of the same absorber after etching with NH3(aq).

\subsection{Morphological and compositional surface-modifications induced by the RbF-PDT}

In Figure 4 scanning electron microscopy (SEM) top view images of a CIGS absorber treated with RbF (PDT-duration: $10 \mathrm{~min}$ ) are shown. Directly after the PDT (Figure 4a) the surface of the CIGS is covered with islands in a size of around $50 \mathrm{~nm}$ to $100 \mathrm{~nm}$ in diameter. Since these islands are not present on the untreated absorber layers (not shown), it is very likely that they consist of $\mathrm{Rb}, \mathrm{F}$ and/or Se. Indeed, energy dispersive X-ray spectroscopy using scanning transmission electron microscopy (STEM-EDX) indicates that the islands contain Rb, F and O (see Figure 5). Figure 5a) shows a high angle annular dark field (HAADF) image on the cross section of the surface area of an RbF-treated CIGS absorber layer. Figures 5b) to h) show elemental maps measured by STEM-EDX on the same area. In the investigated region there is a void visible in between the absorber layer and the covering carbon and platinum protection layers. Within this void an agglomerate can be identified, of which the size fits to one of the islands observed in SEM (highlighted by circles). At the position of this agglomerate higher count rates for $\mathrm{Rb}, \mathrm{F}$ and $\mathrm{O}$ were measured, while there is no $\mathrm{Cu}$, In, Ga or Se detectable. Other regions show similar voids , which all contain higher concentrations of $\mathrm{Rb}$, while $\mathrm{F}$ is only present in some of them probably due to the possible ion-beam damage on $\mathrm{F}$ at thin areas during focused ion beam (FIB) sample preparation. Another example is presented in the supporting information (SI), Figure 1.

Additionally there is a grain boundary visible in the STEM image. A depletion of Se and In as well 

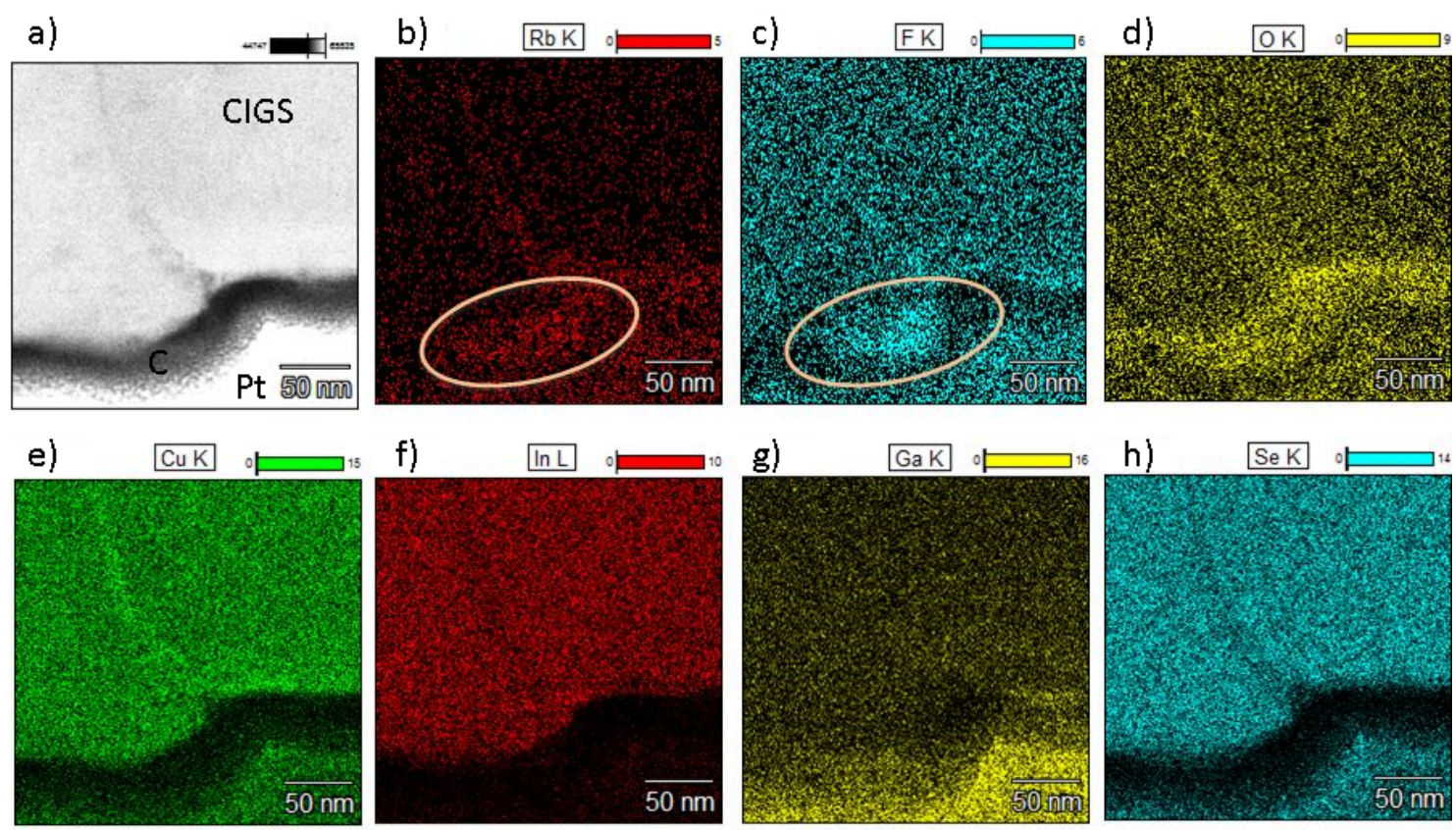

Figure 5: a) STEM-ADF image of the CIGSe's surface covered with RbF as well as carbon and platinum to protect the surface from damage during the focused ion beam preparation.

b) to h): STEM-EDX maps of Rb (b), F (c), O (d), Cu (e), In (f), Ga (g) and Se (h). The surface of the CIGS layer is sharply visible on the Cu-, In- an Se-maps. On the STEM-ADF image there is a void area in between the CIGS layer and the covering $\mathrm{C}$ and Pt layers. This void contains Rb, $\mathrm{F}$ and $\mathrm{O}$. Besides a clear enrichment of $\mathrm{Cu}, \mathrm{Rb}$ and $\mathrm{O}$ at the grain boundary can be seen. 
as an enrichment of $\mathrm{Cu}, \mathrm{O}$ and $\mathrm{Rb}$ at the grain boundary is observed. Similar results (in studies without $\mathrm{Rb}$ ) have been reported previously. ${ }^{[13,14]}$ But also contrary results have been published. ${ }^{[8]}$ After etching the absorber with $\mathrm{NH}_{3}(\mathrm{aq})$ the islands are removed leaving behind a nanostructured surface layer (Figure 4b). This behavior indicates that there are at least two additional "layers" forming at the surface of the CIGS during the RbF-PDT - of which one is soluble in $\mathrm{NH}_{3}(\mathrm{aq})$.

To gain more insights into the compositional evolution of the absorber layer's surface during the RbF-deposition and the subsequent wet chemical treatment, an X-ray Photoelectron Spectroscopy (XPS) study was carried out. A bare CIGS absorber of the reference run was analyzed in comparison with two pieces of the same absorber of the most efficient RbF-treated run $\left(t_{\mathrm{RbF}-\mathrm{PDT}}=10 \mathrm{~min}\right)$. One of the latter samples as well as the reference sample were rinsed in $\mathrm{NH}_{3}(\mathrm{aq})$ prior to the measurements, while the other Rb-treated sample was not. In the following it will be referred to them as "CIGSe $+\mathrm{NH}_{3}$ " for the rinsed but untreated reference sample, "CIGSe/RbF" for the treated but unrinsed sample and "CIGSe/ $\mathrm{RbF}+\mathrm{NH}_{3}$ " for the treated and rinsed sample. From previous studies, ${ }^{[15]}$ it is known that such a rinsing step with $\mathrm{NH}_{3}(\mathrm{aq})$ removes surface oxides and Na-containing compounds. The other $\mathrm{Cu}, \mathrm{In}, \mathrm{Ga}$ and Se contributions are hardly affected.

In Figure 6, the measured data of the key core level peaks as well as the Na KLL Auger electron spectrum are presented with the corresponding data fits. A linear background was substracted from the measured data before the actual fitting using Voigt profiles. The background is not shown in Figure 6. The full width at half maximum (FWHM) of both the Gaussian and the Lorentzian part of the profiles, as well as the energetic position were kept constant for all contributions to one spectrum for all three samples (if present).

After the RbF-PDT there is a strong reduction of the $\mathrm{Cu}-1$, Ga-1 and In-1 contributions in comparison to the untreated reference, which are attributed to the respective metal bound to Se, in the corresponding spectra. While $\mathrm{Cu}-1$ and $\mathrm{Ga}-1$ remain below the detection limit on the rinsed sample, the In-Se contribution (In-1) reappears after rinsing. There are additional contributions in the Ga $2 \mathrm{p}_{3 / 2}$ and In $3 \mathrm{~d}_{5 / 2}$ spectra (Ga-2 and In-2 respectively), which can be attributed to their corresponding oxides. ${ }^{[16,17]}$ While Ga-2 is completely removed by the rinsing step, In-2 partly remains. In combination with the In MNN Auger peak (cf. Figure 2 of the supporting information), 

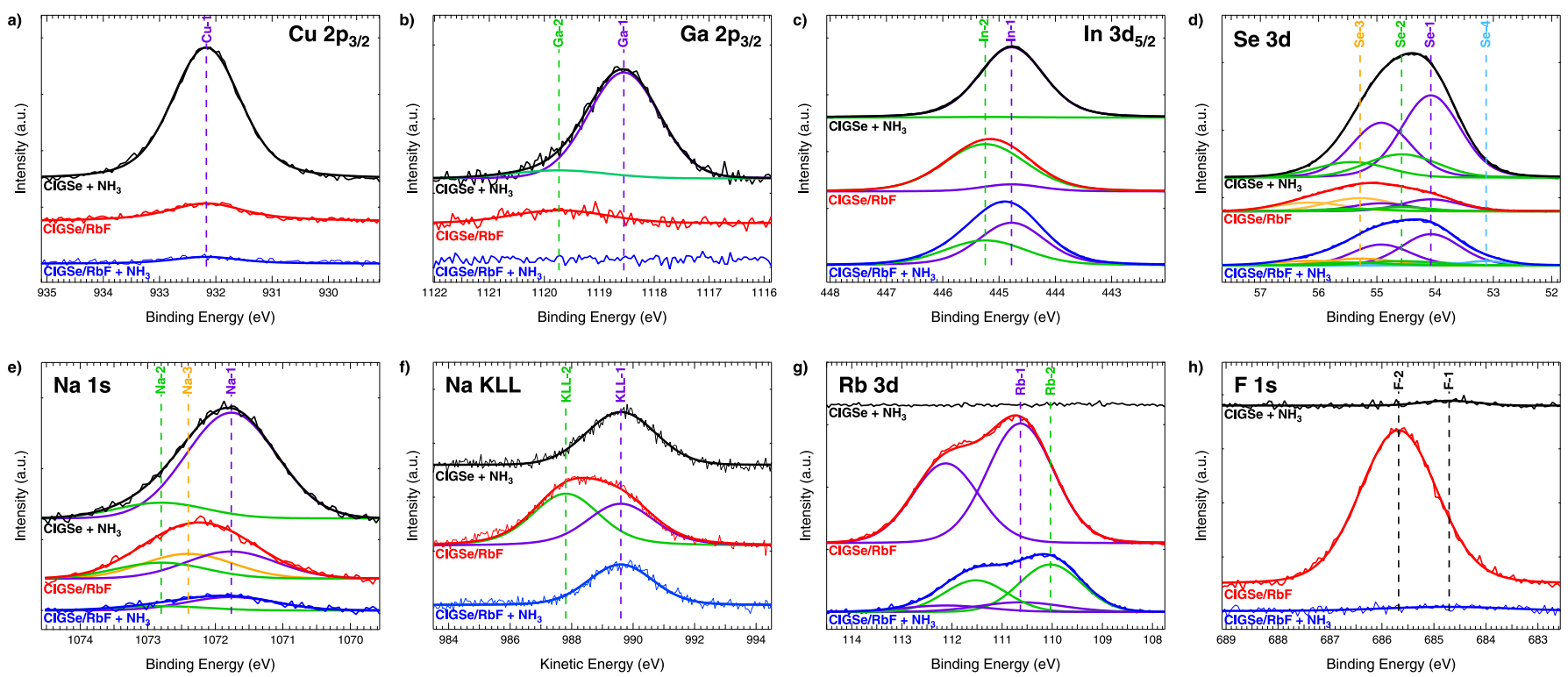

Figure 6: XPS-spectra and corresponding peaks-fits of the $\mathrm{Cu} 2 \mathrm{p}_{3 / 2}$ (a), Ga 2 $\mathrm{p}_{3 / 2}$ (b), In $3 \mathrm{~d}_{5 / 2}$ (c), Se 3d (d), Na 1s (e), Rb 3d (g) and F 1s (h) core levels as well as the Na KLL Auger (f). In case of the $\mathrm{Rb}$ and $\mathrm{Se} 3 \mathrm{~d}$ peaks, we only indicated the corresponding $3 \mathrm{~d} 5 / 2$ sub-levels of each contribution for the sake of clarity.

In-2 in the spectrum of the "CIGS/RbF"-sample can be attributed to a combination of $\operatorname{In}_{2} \mathrm{O}_{3}$ and $\mathrm{In}(\mathrm{OH})_{3}$. While the $\operatorname{In}(\mathrm{OH})_{3}$ is removed by the rinsing step and is not longer observed on the "CIGS $/ \mathrm{RbF}+\mathrm{NH}_{3}$ ", the contribution attributed to $\mathrm{In}_{2} \mathrm{O}_{3}$ stays at least partly. The fact that the energetic position of the In $3 \mathrm{~d}$ line is almost the same for both compounds, ${ }^{[18,19]}$ explains why there is only one additional contribution to the In $3 \mathrm{~d}$ spectrum.

In the $\mathrm{Na} 1 \mathrm{~s}$ spectrum of the "CIGSe $+\mathrm{NH}_{3}$ " as well as in the one of the "CIGSe $/ \mathrm{RbF}+\mathrm{NH}_{3}$ "sample two contributions (Na-1 and $\mathrm{Na}-2$ ) are visible. On the "CIGSe/RbF"-sample an additional contribution Na-3 was detected, which lay energetically between the other two. The presence of two Na-species on the surface of CIGSe was already reported by Heske et al. ${ }^{[20]}$ In combination with the Na KLL Auger electron spectrum (Figure 6f)), the modified Auger parameter $\alpha^{\prime}$ can be calculated for each species. Combining Na-1 with KLL-1 it is found $\alpha_{\mathrm{Na}-1}^{\prime}=(2061.4 \pm 0.2) \mathrm{eV}$, Na-2 combined with KLL-1 leads to $\alpha_{\mathrm{Na}-2}^{\prime}=(2062.4 \pm 0.2) \mathrm{eV}$ and Na-3 and KLL-2 combine to $\alpha_{\mathrm{Na}-3}^{\prime}=(2060.2 \pm 0.2) \mathrm{eV}$. According to the literature, Na-1 can be attributed to $\mathrm{Na}_{2} \mathrm{SeO}_{3},{ }^{[21]} \mathrm{Na}-2$ to $\mathrm{Na}_{2} \mathrm{O},{ }^{[21,22]}$ and $\mathrm{Na}-3$ to $\mathrm{NaF} .{ }^{[23]}$ However, due to the overlap in binding energies of different compounds and since the formation of pure $\mathrm{Na}_{2} \mathrm{O}$ on the surface of CIGS does not seem likely, Na-2 may also be attributed to other sodium-oxides or -hydroxides. 
After the PDT, a strong Rb-1 signal is detectable, which is strongly reduced by the rinsing step giving rise to a second contribution at lower binding energies. Rb-1 can be attributed to RbF, ${ }^{[24]}$ while no literature data could be found for Rb-2. Given the fact that the chemical shift between Rb-1 and Rb-2 is exactly the same as between Na-1 and Na-2 $\left(\Delta_{\mathrm{Rb}}=\Delta_{\mathrm{Na}}=(0.6 \pm 0.2) \mathrm{eV}\right)$, we attribute $\mathrm{Rb}-2$ to an $\mathrm{Rb}-\mathrm{Se}-\mathrm{O}-\mathrm{compound}$ as e.g. $\mathrm{Rb}_{2} \mathrm{SeO}_{3}$.

The fluorine, which is deposited during the RbF-PDT (F-1 in Figure 6f) and is apparently attributed to RbF and $\mathrm{NaF}$ at the CIGSe's surface, is completely removed by the $\mathrm{NH}_{3}(\mathrm{aq})$.

The additional peak at lower binding energies, which is already present in the bare "CIGSe+ $\mathrm{NH}_{3}$ "sample and is still present on "CIGSe $/ \mathrm{RbF}+\mathrm{NH}_{3}$ ", can most likely be attributed to a "ghost peak" of the In $3 \mathrm{~d}_{3 / 2}$-contribution. The energetic distance between $\mathrm{F}-1$ and $\operatorname{In} 3 \mathrm{~d}_{3 / 2}$ is $(232.5 \pm 0.5) \mathrm{eV}$ and therefore fits to the difference of the energies of the $\mathrm{Mg}-\mathrm{K}_{\alpha}$ and the $\mathrm{Al}-\mathrm{K}_{\alpha}$ line $((233.0 \pm 0.4) \mathrm{eV}) .{ }^{[18]}$ The CISSY setup is equipped with a twin anode containing a $\mathrm{Mg}$ - and an Al-excitation source. Possible origins for the appearance of such "ghost peaks" are accidental Al-deposition from the Al-anode onto the Mg-anode or slight misadjustments of the cathode's filament.

The Se 3d spectrum of the "CIGSe+ $\mathrm{NH}_{3}$ "-sample could be fitted by the two doublets, which are attributed with the chalcopyrite phase. ${ }^{[25]}$ After the RbF-PDT Se-1 and Se-2 are strongly reduced, but there is an additional contribution emerging at higher binding energies (Se-3). This contribution can be attributed to the formation of selenium oxides. ${ }^{[16]}$ Taking into account that this species is reduced by rinsing with ammonia solution in a similar manner as the In-2 contribution we assume that an In-Se-O compound is present at the surface after the RbF-PDT. The presence of such a layer has also previously been reported in case of KF-PDT. ${ }^{[26]}$ Additionally there is a fourth component - Se-4 - appearing in the Se core level peak after rinsing. This contribution can either belong to the In-Se bond, as it may be attributed to different $\operatorname{In}_{\mathrm{x}} \mathrm{Se}_{\mathrm{y}}$-phases or it may be attributed to the Rb-Se-O-compound. ${ }^{[25,27]}$ But since there is no contribution visible in the Se 3d spectra being attributed to $\mathrm{Na}_{2} \mathrm{SeO}_{3}$, the allocation to an $\mathrm{In}_{\mathrm{x}} \mathrm{Se}_{\mathrm{y}}$-phase seems more likely. 


\section{Discussion}

\subsection{Beneficial effect of the RbF-PDT: Bulk effects}

We identified a combination of three different mechanisms to be responsible for the increased $V_{\mathrm{OC}}$ of RbF-treated devices. First, there is the increased carrier concentration measured on samples after long RbF-PDTs, which suggests that a combinatory incorporation of $\mathrm{Na}$ and Rb enhances the existing or gives rise to an additional doping mechanism compared to the incorporation of Na alone. At first sight the mechanism enhancing $n_{\mathrm{CV}}$ is not completely conclusive. A direct link of the $C-V$ measurement and the GD-OES-profile of Na seems possible only for very short RbF-PDTs: here, $\mathrm{Rb}$ drives out sodium and therefore the carrier concentration is reduced. The results for longer PDTs on the other hand seem to contradict each other: although more Rb is steadily decreasing the measurable amount of $\mathrm{Na}$ throughout the bulk of the absorber, $n_{\mathrm{CV}}$ is recovering constantly and reaches higher values after very long treatments than the Rb-free reference. However, when considering recent publications regarding these mechanisms, the results become consistent. Two groups investigated the distribution of $\mathrm{Rb}$ in the CIGS on a nanometer scale recently. Schöppe et al. used nano-XRF measurements to prove that in their sample set Rb was clearly present at grain boundaries while concentrations in the grain interiors were below the detection limit of the used method. ${ }^{[5]}$ Similarly Vilalta-Clemente et al. used atom probe tomography (APT) to investigate the same question. ${ }^{[8]}$ The latter study also involved the interaction of $\mathrm{Rb}$ with Na. The authors confirmed that Rb stays mostly at the grain boundary and could not be found within the grains using APT. Furthermore they found out that the presence of $\mathrm{Na}$ at the grain boundaries is less likely in samples with $\mathrm{RbF}$, while the concentration of $\mathrm{Na}$ in the grain interior is strongly increased. Based on these findings, we interpret our results as follows: Initially $\mathrm{Rb}$ replaces $\mathrm{Na}$ at the grain boundaries, which is why $\mathrm{Na}$ is partly driven to the surface of the absorber layer and then later washed away by the rinsing step. After longer PDTs the remaining part of the Na is accumulating in the grain interior, leading to an increase of the carrier concentration. It is interesting to note that this means that the presence of $\mathrm{Rb}$ alone at the grain boundaries does not compensate the resulting drop in $n_{\mathrm{CV}}$. However, the reduced bulk recombination rate could be explained by the 
presence of $\mathrm{Rb}$ at the grain boundaries, as done by Schöppe et al. The authors conclude that $\mathrm{Rb}$ is passivating defects at the grain boundaries. Such a grain boundary passivation mechanism is common for other solar materials such as CdTe. ${ }^{[28]}$ Note that we also found an Rb-enrichment at the grain-boundaries in our STEM-EDX measurements, which is consistent with the findings of the other groups. Nevertheless, an additional, direct doping mechanism of Rb in the grain interiors cannot be completely ruled out, since there might be Rb present within the grains in a concentration below the detection limits of the used measurement techniques.

However, the observed gain in $n_{\mathrm{CV}}$ can only be a partial explanation for the measured $V_{\mathrm{OC}}$-boost. According to literature an increase in $n_{\mathrm{CV}}$ after the PDT can be connected to a maximum difference in $V_{\mathrm{OC}}$ of

$$
\Delta V_{\mathrm{OC}} \leq \frac{k_{\mathrm{B}} T}{q} \ln \frac{n_{20 \mathrm{~min}}}{n_{\mathrm{NoPDT}}} \approx 20 \mathrm{mV}
$$

for the sample with $t_{\mathrm{RbF}-\mathrm{PDT}}=20 \mathrm{~min} .{ }^{[29]}$ The observed gain in $V_{\mathrm{OC}}$ for this sample is in the range of $(40-45) \mathrm{mV}$. Consequently we assume that the RbF-PDT additionally reduces the recombination rate of our devices. This assumption was confirmed in a study we published recently. ${ }^{[30]}$ In that contribution we could prove that the remaining difference in $V_{\mathrm{OC}}$ can be explained by a combination of a reduced recombination rate in the bulk of the absorber layer and a reduced interface recombination velocity.

\subsection{Beneficial effect of the RbF-PDT: Interface effects}

In order to understand the origin of the reduced interface recombination velocity, we try to summarize our results by building a reaction model for the PDT and the consecutive rinsing step. The measured XPS-spectra of the shallow core levels $\left(\mathrm{Cu} 2 \mathrm{p}_{3 / 2}\right.$, Ga 2 $\mathrm{p}_{3 / 2}$, Se 3d) show similar behavior as reported by other groups for a KF-PDT. ${ }^{[31,32]}$ Note that after the PDT we do only see an additional contribution with increased binding energy in the In spectrum, while we do not observe an additional In-species at lower binding energies than In-1. A contribution at lower binding energies than the one attributed to CIGSe has been reported by Handick et al., ${ }^{[32]}$ and was attributed by the authors to a K-In-Se surface layer. On the other hand we do observe an additional species at lower binding energies in the Se-spectrum of the sample "CIGS/RbF $+\mathrm{NH}_{3}$ " (Se-4), which these 


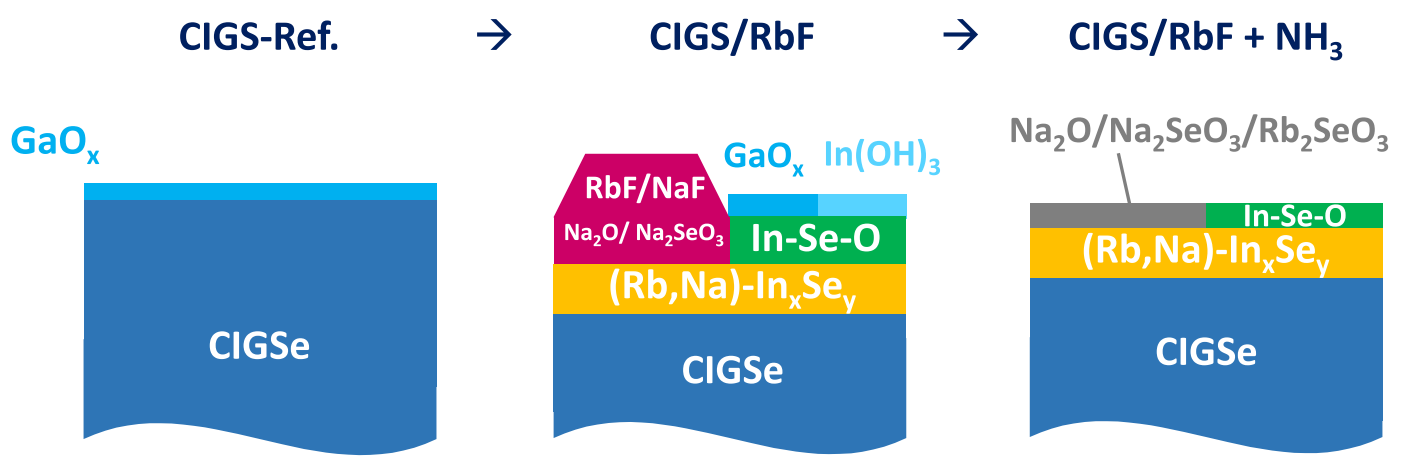

Figure 7: Proposed model of a surface layer formation during the RbF-PDT.

authors also observed in their study. In other contributions regarding the effects of a KF-PDT the authors also did not observe the additional In-species but only the one in the Se $3 \mathrm{~d} .{ }^{[31]}$ Thus, the presence and intensity of these additional contributions might be attributed to the exact growth parameters of the CIGS and the PDT, which are different in all three cases discussed here.

In conclusion, the observations of our XPS-study cannot unambigiously identify the compound that is present on our samples, especially not if it is e.g. $\mathrm{RbInSe}_{2}$, similar to the considerations made in the case of a KF-PDT. ${ }^{[31,33]}$

However, combining all XPS spectra we find evidence for a $\mathrm{Cu}$ - and Ga- depleted CIGS (resulting in $\mathrm{In}_{\mathrm{x}} \mathrm{Se}_{\mathrm{y}}$ )-layer forming at the surface during the RbF-PDT. The fact that alkali-oxides are found at the surface after rinsing $\left(\mathrm{Rb}_{2} \mathrm{SeO}_{3}\right.$ or a similar compound in addition to the already known $\mathrm{Na}_{2} \mathrm{SeO}_{3}$ and $\mathrm{Na}_{2} \mathrm{O}$ ), indicates that $\mathrm{Na}$ and $\mathrm{Rb}$ are incorporated in this $\mathrm{In}_{\mathrm{x}} \mathrm{Se}_{\mathrm{y}}$-layer. Since the $\mathrm{In}_{\mathrm{x}} \mathrm{Se}_{\mathrm{y}}$-layer is only visible with XPS after rinsing the sample, it is likely covered by at least one other layer, which is removed by the $\mathrm{NH}_{3}(\mathrm{aq})$. After removal of this covering layer, the alkaliselenide-oxides are formed due to the short contact with air. Based on the XPS-spectra as well as the SEM and STEM studies we propose that this covering layer is a combination of RbF, NaF and an In-Se-O species (see Figure 7).

Assuming that an alkali-In-Se layer can lead to a reduction of the valence band edge would lead to a suitable explanation for a reduced interface recombination velocity. ${ }^{[7,34]}$

Similar to our findings, a nanopatterning of the CIGSe's surface after an alkali-PDT has already been reported in case of KF-PDT and RbF-PDT. ${ }^{[6,35]}$ In the case of KF-PDT the authors proposed that the nanostructure leads to a passivation of the interface and is therefore reducing the 
recombination velocity, similar to a point contact formation in silicon solar cells. ${ }^{[35,36]}$ Based on our findings the nanopatterning results in Volmer-Weber growth of excess RbF on the treated absorber layer, which is removable by rinsing in $\mathrm{NH}_{3}(\mathrm{aq}) .{ }^{[37]}$ But since the distribution of these "point contacts" is rather dense and the distance between these contacts is small compared to the diffusion length (which we consider to be in the order of magnitude of $\sim 1 \mu \mathrm{m}$ ), ${ }^{[38]}$ we conclude that our findings as well as the following 1D-modelling is not affected by the presence of the nanopatterning. However, it cannot be excluded that the observed reduction of the surface recombination velocity is partly attributed to this nanopatterning. In fact there is a theoretical study, suggesting that such a patterning could reduce the surface recombination velocity. ${ }^{[39]}$

\subsection{Detrimental effect of the RbF-PDT}

The beneficial effects of the RbF-PDT are accompanied by two negative ones, namely the lowering of the FF and the appearance of a pronounced roll-over effect in the illuminated $j-V$-curve. A lower FF due to alkali-incorporation into CIGS absorber layers was already reported in case of NaF-precursors and NaF-PDTs. ${ }^{[38]}$ The authors attributed this behavior (using $C$ - $V$-measurements and numerical simulations) to the creation of additional acceptor-like defects in a $\mathrm{GaO}_{\mathrm{x}}$ layer due to $\mathrm{Na}$ in-diffusion. Based on this observation we built a model explaining the reduced $F F$ after RbF-PDT with the creation of acceptor states at the CdS/ZnO-interface induced by Rb. Since the $\mathrm{ZnO}$ :Al-layer for this work is deposited at substrate temperatures around $165^{\circ} \mathrm{C}$, there might be alkali elements $(\mathrm{Na}, \mathrm{Rb})$ diffusing out of the absorber layer to the newly formed CdS/ZnO-interface during that deposition. Based on DFT-calculations by Park et al., ${ }^{[40]}$ we know that Na and K will create acceptor states in $\mathrm{ZnO}$. The authors calculated the energetic defect levels of $\mathrm{Li}, \mathrm{Na}$ and $\mathrm{K}$ in $\mathrm{ZnO}$ and found that substitutional defects induced by these impurities will create acceptor-like levels close to the valence band maximum (VBM). With increasing size of the atoms, the defect levels move deeper (position relative to the VBM: $0.09 \mathrm{eV}$ for $\mathrm{Li}$ up to $0.32 \mathrm{eV}$ for $\mathrm{K}$ ), suggesting that $\mathrm{Rb}$ would create defects even deeper in the band gap. Experimental findings (regarding Li and $\mathrm{Na}$ ) suggest that these calculations even underestimate the energetic position of the acceptor states. ${ }^{[41,42]}$ 
We used numerical simulations based on SCAPS 1D to test this model using the parameters described in section 5.2 for the RbF-free device. ${ }^{[43]}$ To simulate the migration of Rb-atoms into the $\mathrm{ZnO}$ of the "RbF-treated" device, we introduced acceptor like defects at the CdS/ZnO-interface. Interpreting the mentioned results from the literature carefully, we positioned these defects rather close to the $\operatorname{VBM}\left(E_{\mathrm{A}}=0.3 \mathrm{eV}\right)$ to be sure we are not overestimating their effect. Note, that we didn't introduce any beneficial effects in this model, such as the described enhanced carrier concentration or reduced recombination rates, because here the aim is to merely separate the beneficial from the detrimental effects. The corresponding band diagrams of the "Rb-free reference" and the "RbF-treated" sample as well as the resulting $j$ - $V$-curves are shown in Figure 8 . The $F F$ is lowered by the introduction of the additional defects by approximately $3 \%$, which is in good agreement with the FF-loss observed in our experiment (cf. Figure 1). This effect could also explain results of a study, which was performed by Keller et al. ${ }^{[4]}$ There, the authors investigated the effect of different substrate temperatures during TCO deposition and found that samples with KF-PDT showed lower FF and $V_{\mathrm{OC}}$ after TCO-deposition at elevated temperatures.

However, although the simulated $j$ - $V$-curve actually leads to a lowering of the $F F$, the roll-over effect, which indeed also is present in the simulated curve, is less pronounced than in the measured curve (Figure 3). This leads to the assumption that there may be an additional current blocking barrier forming in the device due to the RbF-PDT, which enhances this roll-over. This could be e.g. a back contact barrier due to the over pronounced Na-depletion next to the back-contact (see Figure 2) or a barrier induced by the newly formed (Rb,Na)- $\operatorname{In}_{x} S_{y}$ layer at the CIGS/CdS-interface as proposed by Weiss et al. ${ }^{[10]}$

\section{Conclusions}

An RbF post deposition treatment on our CIGS absorber layers impacts both the surface and bulk properties of the absorber layer. Based on XPS, SEM and STEM analyses we see strong evidence that an $\mathrm{Rb}$ - and Na-containing $\operatorname{In}_{\mathrm{x}} \mathrm{Se}_{\mathrm{y}}$ layer is formed at the surface of the absorber layer during the RbF-PDT. On top of this surface layer, there is a patterned multilayer containing NaF, $\mathrm{RbF}, \mathrm{In}(\mathrm{OH})_{3}, \mathrm{GaO}_{\mathrm{x}}$ and an In-Se-O-compound. By rinsing in $\mathrm{NH}_{3}(\mathrm{aq})$, all these components 
a)

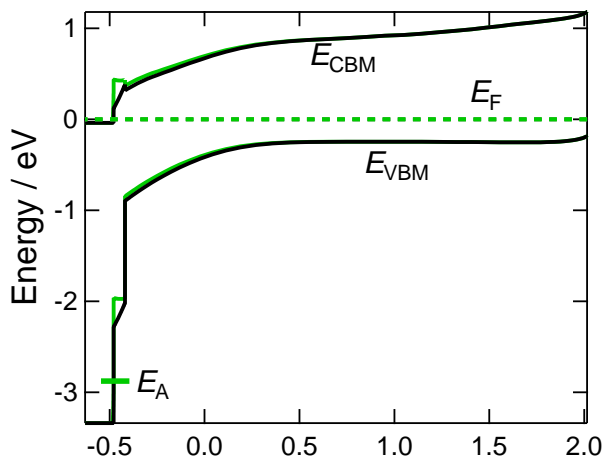

Distance from heterointerface / $\mu \mathrm{m}$

b)

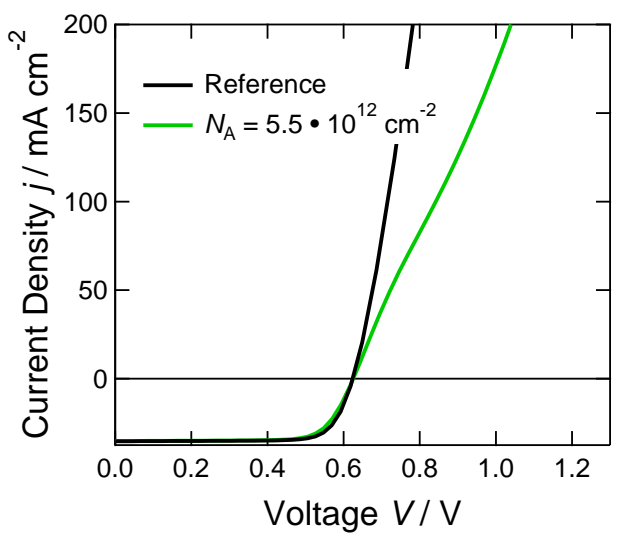

Figure 8: a) SCAPS-simulated energy band diagram of a "standard" CIGS solar cell (black) and the same layer stack after introducing a back contact barrier and acceptor-like defects at the CdS/ZnO-interface. b) The corresponding simulated $j$ - $V$-curve. 
are etched off of the surface - only traces of the In-Se-O remain on the (Rb,Na)- $\operatorname{In}_{\mathrm{x}} \mathrm{Se}_{\mathrm{y}}$ surface. In the CIGS-bulk on the other hand, Rb segregates at the grain boundaries, presumably leading to Na-migration to the surface and into the grain interiors. During device formation, surplus Na and/or Rb from the surface or the grain boundaries seem to diffuse to the newly formed CdS/ZnOinterface.

We attribute the steady $V_{\mathrm{OC}^{-}}$-increase of the corresponding solar cells to a combination of three mechanisms. First, for sufficiently long treatments the carrier concentration of the CIGS absorber layer is increased by the higher concentration of $\mathrm{Na}$ in the grain interiors. Secondly, the recombination rate in the bulk is reduced, possibly due to grain boundary passivation by Rb. Finally also the interface recombination velocity is lowered by the formation of the $(\mathrm{Rb}, \mathrm{Na})-\operatorname{In}_{\mathrm{x}} \mathrm{Se}_{\mathrm{y}}$ surface layer.

Furthermore we explain the reduced $F F$ by the creation of alkali-induced acceptor states at the $\mathrm{CdS} / \mathrm{ZnO}$-interface. This is accompanied by a current blocking barrier leading to a roll-over in the $j$ - $V$-curves. The next step is now to characterize these detrimental effects in more detail, to find the origin of the current blocking barrier and to finally overcome the $F F$-loss while maintaining the beneficial effects of the PDT on the $V_{\mathrm{OC}}$.

\section{Experimental Section}

\subsection{Solar cell fabrication}

The CIGS absorber layers were prepared on $2 \mathrm{~mm}$ thick float glass substrates coated with $800 \mathrm{~nm}$ thick molybdenum, which was deposited by DC-sputtering. There was no Na-diffusion barrier deposited on the glass beforehand allowing for diffusion of $\mathrm{Na}$ from the substrate into the CIGS. The evaporation of the CIGS absorber was done using an adapted three-stage evaporation process as described in detail in ${ }^{[30]}$. The maximum substrate temperature during growth was kept at $530{ }^{\circ} \mathrm{C}$. The final layers exhibited a $\mathrm{Cu}$-poor composition with molar fraction ratios of $\chi_{\mathrm{Cu}} /\left(\chi_{\mathrm{Ga}}+\chi_{\mathrm{In}}\right) \approx 0.9$ and $\chi_{\mathrm{Ga}} /\left(\chi_{\mathrm{Ga}}+\chi_{\mathrm{In}}\right) \approx 0.3$. After finishing the CIGS-layer at the end of stage three, the substrates were cooled down to $280^{\circ} \mathrm{C}$ and kept at this temperature for the RbF-PDT. The RbF was 
evaporated with a fixed source temperature resulting in a deposition rate of approximately $0.2 \frac{\AA}{\mathrm{s}}$ (as measured by quartz crystal microbalance). The duration of the PDT was varied from 0 min for the RbF-free reference sample up to $t_{\mathrm{PDT}}=20 \mathrm{~min}$ - in total seven deposition runs were performed with $0 \mathrm{~min}, 1 \mathrm{~min}, 4 \mathrm{~min}, 7 \mathrm{~min}, 10 \mathrm{~min}, 15 \mathrm{~min}$ and $20 \mathrm{~min}$. Since all other parameters of the PDT, e.g. the evaporation rate of he $\mathrm{RbF}$, were kept constant, this variation of the duration equals a variation of the amount of RbF deposited on the CIGS. The selenium supply, which was strongly reduced during the PDT compared to the CIGS growth, was turned off after finishing the PDT. At the same time the substrates were cooled down to room temperature.

One absorber of each run was directly stored in vacuum and later used for additional characterization. The other absorber layers were rinsed in $\mathrm{NH}_{3}(\mathrm{aq})$ (1 mol/l). Subsequently approximately $50 \mathrm{~nm}$ thick CdS buffer layers were deposited by chemical bath deposition (CBD). Note, that in this study the thickness of the buffer layer was not varied, although it is known that a reduction of the CdS thickness may be beneficial on alkali treated CIGS. ${ }^{[45,46]}$ As transparent front contact a bi-layer of approximately $180 \mathrm{~nm}$ thick i- $\mathrm{ZnO} / \mathrm{ZnO}: \mathrm{Al}$ was deposited by RF-sputtering before finally $\mathrm{Ni} / \mathrm{Al} / \mathrm{Ni}$ finger-grids were evaporated onto the TCO.

\subsection{Characterization and modeling}

The current density-voltage $(j-V-)$ measurements were performed under standard test conditions (AM 1.5 spectrum, $1000 \mathrm{~W} \cdot \mathrm{m}^{-2}, 25^{\circ} \mathrm{C}$ ) using a WACOM A+ solar simulator; SEM images were taken using a Zeiss LEO Gemini 1530; and capacitance-voltage $(C-V-)$ measurements were carried out on a self-built setup using an Agilent 4284A LCR meter at a frequency of $\nu=100 \mathrm{kHz}$. Additionally elemental depth profiles were measured using GD-OES with a Spectruma GDA 650 and XPS was performed at the CISSY-setup, which is described in detail by Lauermann et al. ${ }^{[47]}$ For all measurements performed in this study, the $\mathrm{Mg}-\mathrm{K}_{\alpha}$ line with a transition energy of $E=(1253.6 \pm 0.2) \mathrm{eV}$ was used as excitation source. The pass energy was set to $E_{\text {pass }}=10 \mathrm{eV}$ for the Ga spectrum and to $E_{\text {pass }}=20 \mathrm{eV}$ for all other spectra. The measurements were performed on bare absorber layers (with and without PDT), which were kept in vacuum after the deposition. The air exposure during the transfer into the XPS-system was kept to a minimum. 
Samples for the STEM measurements were prepared with a Thermo Scientific FEI Scios DualBeam FIB-SEM instrument. The FIB-SEM instrument is equipped with a field emission electron gun (FEG), a gallium liquid metal ion source and an EasyLift micromanipulator. A C-Gas and a Pt-Gas injection system were used to deposit $\mathrm{C}$ and Pt layers on the sample surface for protection from $\mathrm{Ga}$ ion beam damage. From rough cut towards finer thinning of the specimens, a Ga-ion beam with progressively lower voltages from $30 \mathrm{kV}$ to $1 \mathrm{kV}$ and progressively lower ion beam currents from $65 \mathrm{nA}$ to $16 \mathrm{pA}$ has been used. Then a Fischione Nanomill 1040 with low- kV $(0.5 \mathrm{kV}-1 \mathrm{kV})$ Ar beam was used for the final thinning and cleaning of the specimens to $\sim 50 \mathrm{~nm}$ thickness. STEM investigations were performed using a JEOL JEM-ARM 200CF electron microscope equipped with a cold FEG, a CEOS DCOR probe corrector, a Gatan GIF Quantum ERS electron energy-loss spectrometer (EELS), and a $100 \mathrm{~mm}^{2}$ JEOL Centurio EDX detector. The operating voltage is $200 \mathrm{kV}$, with a semi-convergence angle of $20.4 \mathrm{mrad}$ and a probe size of $\sim 1 \AA$. For STEM HAADF imaging, a collection semi-angle of $115 \mathrm{mrad}-276 \mathrm{mrad}$ was used. For EELS the collection semi-angle was $115 \mathrm{mrad}$.

Numerical simulations were done using the SCAPS-1D software, which is available via the University of Gent. ${ }^{[43]}$ A layer stack was set up to represent our Rb-free reference devices based on the literature. ${ }^{[48]}$ Generally a combination of $\mathrm{CuInSe}_{2}$ and $\mathrm{CuGaSe}_{2}$ charateristic properties are used for the absorber layer and their ratio, the layer depth as well as elemental gradients were determined by GD-OES profiling of a real device. The absorption coefficients of $\mathrm{CuInSe}_{2}, \mathrm{CuGaSe}_{2}$ and $\mathrm{ZnO}$ have been determined via reflectance and transmission measurements and additionally the reflectance of the surface of the finished device was measured. In order to account for the shading due to the front contact grid, the illumination intensity was set to $97 \%$. The shallow acceptor density was derived from $C-V$ measurements.

Within the absorber of the reference device, the model contains a single acceptor-like and a donorlike bulk defect, located $0.2 \mathrm{eV}$ above the valence band and below the conduction band, respectively. The defect densities of these defects are correlated to the local Ga-content according to reference ${ }^{[49]}$, with a defect concentration of $5 \cdot 10^{15} \mathrm{~cm}^{-3}$ for $\mathrm{CuInSe}_{2}$ and $5 \cdot 10^{16} \mathrm{~cm}^{-3}$ for $\mathrm{CuGaSe}_{2}$. At the CIGS/CdS-interface, again a donor-like and an acceptor-like defect were placed $0.3 \mathrm{eV}$ and $0.4 \mathrm{eV}$ 
below the conduction band, both with a defect concentration of $4 \cdot 10^{11} \mathrm{~cm}^{-3}$. Defects in the buffer and window layer are assumed to be electrically neutral, positioned in the middle of the band gap.

\section{Acknowledgments}

The authors acknowledge financial support by the German Federal Ministry for Economic Affairs and Energy in the frame of the speedCIGS project (contract number 0324095E). Furthermore we thank our colleagues at HZB for finishing the solar cells as well as R. Klenk, R. Wenisch, T. Bertram, N. Maticiuc, R. Scheer (University of Halle-Wittenberg), N. Barreau and his colleagues at the IMN for fruitful discussions.

\section{References}

[1] J. Hedström, H. Ohlsen, M. Bodegard, A. Kylner, L. Stolt, D. Hariskos, M. Ruckh, H. W. Schock. $\mathrm{ZnO} / \mathrm{CdS} / \mathrm{Cu}(\mathrm{In}, \mathrm{Ga}) \mathrm{Se}_{2}$ thin film solar cells with improved performance. Conference record of the 23rd IEEE Photovoltaic Specialists Conference, pages 364-371, 1993.

[2] P. Jackson, D. Hariskos, E. Lotter, S. Paetel, R. Wuerz, R. Menner, W. Wischmann, M. Powalla. New world record efficiency for $\mathrm{Cu}(\mathrm{In}, \mathrm{Ga}) \mathrm{Se}_{2}$ thin-film solar cells beyond 20\%. Prog. Photovolt: Res. Appl., 19:894, 2011.

[3] Solar Froniter KK. Solar Frontier Achieves World Record Thin-Film Solar Cell Efficiency of 22.9\%. Press Release, 2017.

[4] P. Jackson, R. Wuerz, D. Hariskos, E. Lotter, W. Witte, M. Powalla. Effects of heavy alkali elements in $\mathrm{Cu}(\mathrm{In}, \mathrm{Ga}) \mathrm{Se}_{2}$ solar cells with efficiencies up to $22.6 \%$. physica status solidi (RRL)Rapid Research Letters, 10(8):583, 2016.

[5] P. Schöppe, S. Schönherr, R. Wuerz, W. Wisniewski, G. Martínez-Criado, M. Ritzer, K. Ritter, C. Ronning, C. S. Schnohr. Rubidium segregation at random grain boundaries in $\mathrm{Cu}(\mathrm{In}, \mathrm{Ga}) \mathrm{Se}_{2}$ absorbers. Nano Energy, 42:307, 2017. 
[6] E. Avancini, R. Carron, T. P. Weiss, C. Andres, M. Bürki, R. Figi, Y. E. Romanyuk, S. Buecheler, A. N. Tiwari. Effects of rubidium fluoride and potassium fluoride post deposition treatments on $\mathrm{Cu}$ ( In , Ga ) Se2 thin films and solar cell performance. Chem. Mater., 29(22): 9695, 2017.

[7] D. Hauschild, D. Kreikemeyer-Lorenzo, P. Jackson, T. M. Friedlmeier, D. Hariskos, F. Reinert, M. Powalla, C. Heske, L. Weinhardt. Impact of a RbF Post-Deposition Treatment on the Electronic Structure of the $\mathrm{CdS} / \mathrm{Cu}(\mathrm{In}, \mathrm{Ga}) \mathrm{Se}_{2}$ Heterojunction in High-Efficiency Thin-Film Solar Cells. ACS Energy Letters, 2(10):2383, 2017.

[8] A. Vilalta-Clemente, M. Raghuwanshi, S. Duguay, C. Castro, E. Cadel, P. Pareige, P. Jackson, R. Wuerz, D. Hariskos, W. Witte. Rubidium distribution at atomic scale in high efficient $\mathrm{Cu}(\mathrm{In}, \mathrm{Ga}) \mathrm{Se}_{2}$ thin-film solar cells. Applied Physics Letters, 112(10):103105, 2018.

[9] M. Malitckaya, H.-P. Komsa, V. Havu, M. J. Puska. Effect of alkali metal atom doping on the $\mathrm{CuInSe}_{2}$-based solar cell absober. The Journal of Physical Chemistry C, 121:15516, 2017.

[10] T. P. Weiss, S. Nishiwaki, B. Bissig, R. Carron, E. Avancini, J. Löckinger, S. Buecheler, A. N. Tiwari. Injection current barrier formation for RbF Postdeposition-treated $\mathrm{Cu}(\mathrm{In}, \mathrm{Ga}) \mathrm{Se}_{2^{-}}$ based solar cells. Advanced Materials Interfaces, 5:1701007, 2018.

[11] S. Ishizuka, N. Taguchi, J. Nishinaga, Y. Kamikawa, S. Tanaka, H. Shibita. Group III elemental composition dependence of RbF postdeposition treatment effects on $\mathrm{Cu}(\mathrm{In}, \mathrm{Ga})_{2}$ thin films and solar cells. The Journal of Physical Chemistry C, 122(7):3809, 2018.

[12] P. Pistor, D. Greiner, C. A. Kaufmann, S. Brunken, M. Gorgoi, A. Steigert, W. Calvet, I. Lauermann, R. Klenk, T. Unold, M. C. Lux-Steiner. Experimental indication for band gap widening of chalcopyrite solar cell absorbers after potassium fluoride treatment. Applied Physics Letters, 105(6):63901, 2014.

[13] O. Cojocaru-Mirédin, P.-P. Choi, D. Abou-Ras, S. S. Schmidt, R. Caballero, D. Raabe. Characterization of Grain Boundaries in $\mathrm{Cu}(\mathrm{In}, \mathrm{Ga}) \mathrm{Se}_{2}$ Films Using Atom-Probe Tomography. IEEE Journal of Photovoltaics, 1(2):207, 2011. 
[14] E. Simsek Sanli, Q. M. Ramasse, R. Mainz, A. Weber, D. Abou-Ras, W. Sigle, P. A. van Aken. Evidence for $\mathrm{Cu}_{2-X}$ Se platelets at grain boundaries and within grains in $\mathrm{Cu}(\mathrm{In}, \mathrm{Ga}) \mathrm{Se}_{2}$ thin films. Applied Physics Letters, 111(032103):032103, 2017.

[15] J. Lehmann, S. Lehmann, I. Lauermann, T. Rissom, C. A. Kaufmann, M. C. Lux-Steiner, M. Bär, S. Sadewasser. Reliable wet-chemical cleaning of natively oxidized high-efficiency $\mathrm{Cu}(\mathrm{In}, \mathrm{Ga}) \mathrm{Se}_{2}$ thin-film solar cell absobers. Journal of Applied Physics, 116:233502, 2014.

[16] A. J. Nelson, S. Gebhard, L. L. Kazmerski, E. Colavita, M. Engelhardt, H. Höchst. Characterization of the native oxide of $\mathrm{CuInSe}_{2}$ using synchrotron radiation photoemission. Applied Physics Letters, 57(1428):1, 1990. doi: 10.1063/1.104122.

[17] K. Otte, G. Lippold, D. Hirsch, A. Schindler, F. Bigl. XPS and raman investigations of nitrogen ion etching for depth profiling of $\mathrm{CuInSe}_{2}$ and $\mathrm{CuGaSe}_{2}$. Thin Solid Films, 362:498, 2000.

[18] J. F. Moulder, W. F. Stickle, P. E. Sobol, K. D. Bomben. Handbook of X-Ray Photoelectron Spectroscopy. Perkin-Elmer Corporation, 1992.

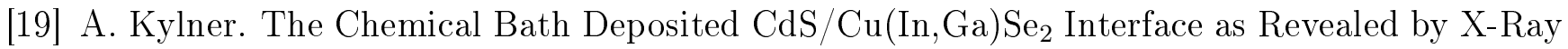
Photoelectron Spectroscopy. Journal of The Electrochemical Society, 146(5):1816, 1999.

[20] C. Heske, R. Fink, E. Umbach, W. Riedl, F. Karg. Na-induced effects on the electronic structure and composition of $\mathrm{Cu}(\mathrm{In}, \mathrm{Ga}) \mathrm{Se}_{2}$ thin-film surfaces. Applied Physics Letters, 68 $(24): 3431,1996$.

[21] D. W. Niles, K. Ramanathan, F. Hasoon, R. Noufi, B. J. Tielsch, J. E. Fulghum. Na impurity chemistry in photovoltaic CIGS thin films: Investigation with x-ray photoelectron spectroscopy. Journal of Vacuum Science \& Technology A: Vacuum, Surfaces, and Films, 15 (6):3044, 1997.

[22] A. Barrie, F. J. Street. An Auger and X-ray photoelectron spectroscopic study of sodium metal and sodium oxide. Journal of Electron Spectroscopy and Related Phenomena, 7(1):1, 1975 . 
[23] H. Seyama, M. Soma. X-ray photoelectron spectroscopic study of the effect of heating on montmorillonite containing sodium and potassium cations. Clays and Clay Minerals, 34(6): 672, 1986.

[24] W. E. Morgan, J. R. Van Wazer, W. J. Stec. Inner-Orbital Photoelectron Spectroscopy of the Alkali Metal Halides, Perchlorates, Phosphates, and Pyrophosphates. Journal of the American Chemical Society, 95(3):751, 1973.

[25] B. Canava, J. Vigneron, A. Etcheberry, J. F. Guillemoles, D. Lincot. High resolution XPS studies of Se chemistry of a Cu(In,Ga)Se ${ }_{2}$ surface. Applied Surface Science, 202:8, 2002.

[26] E. Handick, P. Reinhard, R. G. Wilks, F. Pianezzi, R. Félix, M. Gorgoi, T. Kunze, S. Buecheler, A. N. Tiwari, M. Bär. NaF / KF Post-Deposition Treatments and their Influence on the Structure of $\mathrm{Cu}(\mathrm{In}, \mathrm{Ga}) \mathrm{Se}_{2}$ Absorber Surfaces. IEEE PVSC, 43:17, 2016.

[27] I. Miyake, T. Tanpo, C. Tatsuyama. Related content XPS Study on the Oxidation of InSe. Japanese Journal of Applied Physics, 23(2):172, 1984.

[28] C. Li, J. Poplawsky, Y. Yan, S. J. Pennycook. Understanding individual defects in CdTe thin-film solar cells via STEM: From atomic structure to electrical activity. Materials Science in Semiconductor Processing, 65:64, 2017.

[29] R. Scheer, H.-W. Schock. Chalcogenide Photovoltaics. WILEY-VCH, 2011.

[30] M. D. Heinemann, T. Kodalle, C. Hages, M. Klupsch, D. Greiner, L. Korte, S. Levcenco, T. Unold, R. Schlatmann, C. A. Kaufmann. Evaluation of recombination losses in thin film solar cells using an LED sun simulator - the effect of RbF post-deposition on CIGS solar cells. Submitted to EPJ Photovoltaics, 2018.

[31] T. Lepetit, G. Ouvrard, N. Barreau. KF post deposition treatment in co-evaporated $\mathrm{Cu}(\mathrm{In}, \mathrm{Ga}) \mathrm{Se}_{2}$ thin film solar cells : Beneficial or detrimental effect induced by the absorber characteristics. Prog. Photovolt: Res. Appl., 25:1068, 2017. 
[32] E. Handick, P. Reinhard, R. G. Wilks, F. Pianezzi, T. Kunze, D. Kreikemeyer-Lorenzo, L. Weinhardt, M. Blum, W. Yang, M. Gorgoi, E. Ikenaga, D. Gerlach, S. Ueda, Y. Yamashita, T. Chikyow, C. Heske, S. Buecheler, A. N. Tiwari, M. Bär. Formation of a K-In-Se surface species by $\mathrm{NaF} / \mathrm{KF}$ post-deposition treatment of $\mathrm{Cu}(\mathrm{In}, \mathrm{Ga}) \mathrm{Se}_{2}$ thin-film solar cell absorbers. ACS Applied Materials \& Interfaces, 2:3581, 2017.

[33] T. Lepetit, S. Harel, L. Arzel, G. Ouvrard, N. Barreau. Coevaporated KInSe 2 : A Fast Alternative to KF Postdeposition Treatment in High-Efficiency Cu(In,Ga)Se $\mathrm{S}_{2}$ Thin Film Solar Cells. 6(5):1316, 2016.

[34] E. Handick, P. Reinhard, J. H. Alsmeier, L. Köhler, F. Pianezzi, S. Krause, M. Gorgoi, E. Ikenaga, N. Koch, R. G. Wilks, S. Buecheler, A. N. Tiwari, M. Bär. Potassium Postdeposition Treatment-Induced Band Gap Widening at $\mathrm{Cu}(\mathrm{In}, \mathrm{Ga}) \mathrm{Se}_{2}$ Surfaces - Reason for Performance Leap? ACS Applied Materials and Interfaces, 7(49):27414, 2015.

[35] P. Reinhard, B. Bissig, F. Pianezzi, H. Hagendorfer, G. Sozzi, R. Menozzi, C. Gretener, S. Nishiwaki, S. Buecheler, A. N. Tiwari. Alkali-templated surface nanopatterning of chalcogenide thin films: A novel approach toward solar cells with enhanced efficiency. Nano Letters, $15(5): 3334,2015$.

[36] J. Zhao, A. Wang, M. A. Green. 24.5\% Efficiency Silicon PERT Cells on MCZ Substrates and 24.7\% Efficiency PERL Cells on FZ Substrates. Progress in Photovoltaics: Research and Applications, 474:471, 1999.

[37] M. Volmer, A. Weber. Keimbildung in übersättigten Gebilden. Zeitschrift f. physikalische Chemie, 119:277, 1926.

[38] M. D. Heinemann, D. Greiner, T. Unold, R. Klenk, R. Schlatmann, C. A. Kaufmann. The Importance of Sodium Control in CIGSe Superstrate Solar Cells. IEEE, 5(1):378, 2015.

[39] A. Bercegol, B. Chacko, R. Klenk, I. Lauermann, M. C. Lux-Steiner, M. Liero. Point contacts at the copper-indium-gallium-selenide interface - a theoretithe outlook. Journal of Applied Physics, 119:155304, 2016. 
[40] C. H. Park, S. B. Zhang, S.-H. Wei. Origin of p -type doping difficulty in ZnO: The impurity perspective. Physical Review B, 66(7):073202, 2002.

[41] D. Zwingel. Trapping and recombination processes in the thermoluminescence of Li-doped ZnO single crystals. Journal of Luminescence, 5(6):385, 1972.

[42] B. K. Meyer, J. Stehr, A. Hofstaetter, N. Volbers, A. Zeuner, J. Sann. On the role of group I elements in ZnO. Applied Physics A, 88(1):119, 2007.

[43] M. Burgelman, P. Nollet, S. Degrave. Modelling polycrystalline semiconductor solar cells. Thin Solid Films, 361:527, 2000.

[44] J. Keller, F. Chalvet, J. Joel, A. Aijaz, T. Kubart, L. Riekehr, M. Edoff, L. Stolt, T. TÃ Irndahl. Effect of KF absorber treatment on the functionality of different transparent conductive oxide llayer in CIGSe solar cells. Progress in Photovoltaics: Research and Applications, 1:11, 2017.

[45] A. Chirilă, P. Reinhard, F. Pianezzi, P. Bloesch, A. R. Uhl, C. Fella, L. Kranz, D. Keller, C. Gretener, H. Hagendorfer, D. Jaeger, R. Erni, S. Nishiwaki, S. Buecheler, A. N. Tiwari. Potassium-induced surface modification of $\mathrm{Cu}(\mathrm{In}, \mathrm{Ga}) \mathrm{Se}_{2}$ thin films for high-efficiency solar cells. Nature Materials, 12(12):1107, 2013.

[46] T. M. Friedlmeier, P. Jackson, D. Kreikemeyer-Lorenzo, D. Hauschild, O. Kiowski, D. Hariskos, L. Weinhardt, C. Heske, M. Powalla. A Closer Look at Initial CdS Growth on High-Efficiency $\mathrm{Cu}(\mathrm{In}, \mathrm{Ga}) \mathrm{Se}_{2}$ Absorbers Using Surface-Sensitive Methods. IEEE PVSC, 43: $457,2016$.

[47] I. Lauermann, A. Steigert. CISSY : A station for preparation and surface / interface analysis of thin film materials and devices. Journal of Large-Scale Research Facilities, A67:4, 2016.

[48] M. Gloeckler, A. L. Fahrenbruch, J. R. Sites. Numerical modeling of CIGS and CdTe solar cells: setting the baseline. Proceedings of 3rd WCPEC, 1:491, 2003. 
[49] G. Hanna, A. Jasenek, U. Rau, H. W. Schock. Influence of the Ga-content on the bulk defect densities of $\mathrm{Cu}(\mathrm{In}, \mathrm{Ga}) \mathrm{Se}_{2}$. Thin Solid Films, 387(1-2):71, 2001. 